vector over a sphere of large radius is briefly treated. On p. 114 the well-known integral involved in the radiation resistance of a half-wave dipole is incorrectly stated and is not evaluated.

Chapters 3,4 and 5 deal with the properties of reflectors having the form of an infinite flat sheet, a $\mathrm{V}$ and a semi-infinite sheet; together with the two following chapters on problems involving cylinders, they form the most valuable part of the theoretical section of the book. However, the relatively large number of errors in the mathematics and the some. what laboured treatment of parts of the analysis may prove a hindrance to the radio engineer who is not well equipped mathematically. The fundamental topic of the single isolated aerial is not introduced until Chapter 8, and it is unfortunate that Section 8.2 on the radiation resistance and power gain of a linear aerial is inaccurate-Fig. 8.6 has the ordinate axis incorrectly labelled, and Table 8.1 gives the radiation resistance of a dipole referred to the current antinode and not to the mid-point as stated.

The more exact approaches to the impedance of a linear aerial given by various workers during the past twelve years receives scant attention in Section 8.4, and it is felt that a useful opportunity to give a comparative summing-up of these theories was missed. It is surprising that the author still regards as controversial the identity of the resistance of an aerial in the transmitting and receiving conditions. Chapters 9-14 constitute the experimental section and also contain some fresh theoretical material. These chapters contain very useful information on the practical design, the performance and the testing of aerial arrays and parabolic reflectors.

In summing up, it is suggested that the value of a future edition of the book would be enhanced by a reduction of its length, which would be possible without a sacrifice of useful information, and by a fuller presentation of the established results for the single aerial which forms the basic element of any practical array.

R. E. Burgess

\section{A FISH FARMER'S COMPANION}

\section{Fortschrittliche Karpfenteichwirtschaft}

Ergebnisse 20 jähriger Untersuchungen auf dem Gebiete der Teichforschung. Von Prof. Wilhelm Wunder. Pp. vi $+385+11$ plates. (Stuttgart: E. Schweizerbart'sche Verlagsbuchhandlung (Erwin Nägele), 1949.) n.p.

7 HIS is a thorough treatise on carp farming in which almost half the book is devoted to the food of the carp, whether natural or artificial. In Chapter 2, the principles controlling fish production in carp ponds are set out in their complex interrelationships of stock density, natural food (stimulated by fortilization and cultivation) and added fodder. It is rather surprising to find how important a part is played by the zooplankton as a natural food for the carp. The carp tends to become increasingly a macroplanktonic feeder as it grows larger and older. The weighted percentage of zooplanktonic food, in the total food taken, increases from 22 in the first, to 75 in the fourth year, with a corresponding decrease in bottom and littoral organisms. The latter, however, play an important part in late summer, autumn and winter, when the plankton has died down. In poor and neglected ponds also, where the plankton shows only feeble development and dies away early, the carp are forced to rely almost wholly on bottom and littoral organisms, of which chironomids are the most important.

The author shows the importance of a period of dry fallow; and green manuring, which may take the form of flooding a pond in which a land crop is growing, is recommended as providing a substratum for chronomids and other fish food. For the stimulation of the plankton, the colour of which will afford the best indication of the fertilizer requirements, organic manures may be used; but, owing to their scarcity, by far the greater space is devoted to inorganic manures. However, it is interesting to read the author's approval of keeping ducks in fishponds. These birds do not harm healthy and vigorous fry, and their droppings are a valuable manure.

Among the inorganic manures, the greatest importance is attributed to lime, and next to phosphate. Superphosphate can produce an average increase of yield of 96 per cent, and repay its cost 1,000 per cent. The dosage required is small, of the order of $1 \mathrm{cwt}$. per acre annually. Potash produces no certain improvement except perhaps in very poor ponds. The same uncertainty applies to nitrogenous fertilizers - an interesting difference between agriculture and aquiculture. Unlike phosphate, which when used together with lime is the most profitable fertilizer, nitrogenous fertilizers do not give consistent increases in the yield of ponds. Recent work on the fixation of atmospheric nitrogen by $\mathrm{De}^{1}$ and Fogg ${ }^{2}$ proves that very substantial amounts of nitrogen can be fixed, in bacteria-free culture, by blue-green algæ, and Wunder shows that Anabcena, the blue-green algæ chiefly investigated by $\mathrm{De}$ and Fogg, is a dominant planktont in fishponds. These authors found, however, that nitrogen fixation is inhibited by the presence of readily available combined nitrogen ; it seems, therefore, that the addition of expensive nitrogenous fertilizers can make little difference to the yield of a pond.

In a section on fodder for carp, the author shows that a balanced ration of protein and carbohydrate gives the best results; he describes the value of the potato as carp food, especially in well-cultivated and fertilized ponds where abundant protein, in the form of zooplankton, is already present. The artificial feeding of carp may double the yield, yet most of the fodders listed are suitable for direct human consumption. In few territories is there a readily available cheap fodder, surplus to human requirements; and surely the value of fish farming, as a technique, lies in the rapid and complete synthesis of cheap organic and inorganic manures into firstclass protein by way of a short food-chain.

Chapter 5 deals with changes of body form due to the environment (Hungerform and Mastform); but Chapter 7 shows that hereditary differences closely resemble these environmental differences. Both, again, must be considered in relation to Lebensraum, far too briefly discussed. It is easy to understand, but difficult to explain, why small ponds produce small fish, and large ponds large fish; Fig. 52, for example, compares a three-year old fish weighing $34 \mathrm{gm}$. from a small pond, with a one-year old fish weighing $610 \mathrm{gm}$. from a large pond. In a future edition, I would like to see Lebensraum more fully discussed, and its effects distinguished from hereditary and environmental factors which make 'bad-doers' among pond fish.

C. F. HICKIING

2 Fogg, \& $\mathrm{F}, \mathrm{Br}$ 